\title{
CATEGORIZATION OF BRAZILIAN INTERNET USERS AND ITS IMPACTS ON THE USE OF ELECTRONIC GOVERNMENT SERVICES
}

\author{
Marcelo Henrique de Araujo \\ Nicolau Reinhard \\ Universidade de São Paulo, São Paulo, SP, Brasil
}

\begin{abstract}
This paper aims to categorize Brazilian Internet users according to the diversity of their online activities and to assess the propensity of these Internet users' groups to use electronic government (e-gov) services. The Amartya Sen's Capability Approach was adopted as the theoretical framework for its consideration of people's freedom to decide on their use of available resources and their competencies for these decisions, leading to the use of e-gov services. Multivariate statistical techniques were used to perform data analysis from the 2007, 2009 and 2011 editions of ICT Household Survey. The results showed that Internet users belonging to the advanced and intermediate use groups were more likely to use e-gov services than those who belong to the sporadic use group. Moreover, the results also demonstrated that the Internet user group of intermediate use presented a higher tendency to use e-gov services than the Internet user group of advanced use. This tendency is possibly related to the extensive use of interactive and collaborative activities of leisure and entertainment performed by this type of user. The findings of this research may be useful in guiding public policies for the dissemination and provision of electronic government services in Brazil.
\end{abstract}

Keywords: e-government services, innovation adoption, Brazil, Internet, Sen's Capability Approach

\footnotetext{
Manuscript first received/Recebido em: 01/06/2015 Manuscript accepted/Aprovado em: 26/04/2016

Address for correspondence / Endereço para correspondência

Marcelo Henrique de Araujo, Ph.D Candidate in Business Administration at the School of Economics, Administration and Accounting of the University of Sao Paulo (FEA-USP). He has a master's degree (MSc) in Business Administration at FEA-USP and Bachelor in Information Systems at University of Sao Paulo. School of Economics, Administration and Accounting, University of São Paulo. Av. Prof. Luciano Gualberto, 908. 05508-010. São Paulo - Brazil. E-mail: marcelo.haraujo@usp.br

Nicolau Reinhard, Senior professor of management at the School of Economics, Administration and Accounting of the University of São Paulo, Brazil. Professor Reinhard has a degree in engineering, a PhD in management, and, besides his academic career, has held executive and consulting positions in IT management in private and public organizations. School of Economics, Administration and Accounting of the University of São Paulo, Av. Prof. Luciano Gualberto, 908. 05508-010 São Paulo - Brazil. E-mail: reinhard@usp.br
} 


\section{INTRODUCTION}

The government is one of the sectors that have been using Information and Communication Technology (ICT) innovations in order to increase the offer of public services to citizens and improve their effectiveness and quality. These initiatives that are based on the use of ICTs and that redefine the interaction between government and society (citizens, companies, non-profit organizations etc.) are known as electronic government (e-gov) (Barbosa, Pozzebon \& Diniz, 2013; Cunha \& Miranda, 2013).

Due to the complexity and variety of initiatives that e-gov comprises, these are classified in three major categories of e-gov applications: (i) public administration; (ii) electronical services (e-services) and (iii) electronic democracy (Cunha \& Miranda, 2013). The first group comprises the use of ICT to improve the management of government activities, administrative processes and resource usage, and also the formulation, implementation, monitoring and control of public policies. The second one (e-services) referers to the use of ICT for the communication and the provision of services in electronic form to citizens and private organizations. The last one covers the use of ICT resources to allow citizens to become better informed about the government, and to facilitate their increasing participation in forming public opinion and in decision making processes (Cunha \& Miranda, 2013; Araujo \& Reinhard, 2015). The discussion purposed in this paper focuses on e-services.

In Brazil, e-government (e-gov) initiatives have become popular among the citizens due to the diversity of electronic services available to the population, such as the electronic voting system, the filing of an income tax return report, the scheduling of medical appointments, and the enrollment of students in public schools, among others (Avgerou, Ganzaroli, Poulymenakou, \& Reinhard, 2009; Reinhard \& Moya, 2002). However, the success of these initiatives (e-gov) depends on the access and predisposition to use the ICT resources in the interaction between the government and the civil society.

Public policies for digital inclusion in the country encourage both the individual access (through tax reduction on computer equipment, promoting the purchase of computers and access to the Internet) and the collective access, which includes the offer and availability of Internet access in public access centers, for example, Public Telecenters and Cybercafés (Lemos \& Martini, 2010; Mori \& Assumpção, 2007; Madon, Reinhard, Roode, \& Walsham, 2009).

Through its Regional Center for Studies on the Development of the Information Society (CETIC.br), the Brazilian Internet Steering Committee (CGI.br) conducts surveys in order to generate statistics about the use of Information and Communication Technologies (ICTs). For the purposes of this paper, the data used were taken from their ICT Household Survey, a survey conducted annually and whose data enable the generation of indicators about the availability and use of the Internet by the Brazilian population.

This research is based on the following objectives: (i) Categorize Internet users based on their Internet use (for example, personal communications, entertainment, business applications, etc.) and (ii) Explore the relationships of their predisposition to use e-gov services with the abovementioned categories. The analysis is based on the ICT Household Survey micro-data for the years 2007, 2009 and 2011. The Capability 
Approach (Sen, 1999) was adopted as the theoretical framework, for its consideration of people's freedom to decide on their use of available resources and their competencies for these decisions, leading to the use of e-government services.

Although the theme has already been explored by Araujo and Reinhard (2015), the contribution of this paper is the characterization of the different groups of Internet users based on their usage of the Internet - and assessing the propensity to use the e-gov in each one of these groups.

The paper is structured as follows: Section 2 discusses the theoretical principles that guide this research. In Section 3, the reference model and the adopted methodological strategy are presented. Section 4 discusses the main results and findings of this research. Section 5 presents final remarks.

\section{LITERATURE REVIEW}

\subsection{The Capability Approach}

The Capability approach (Sen, 1999) was developed in order to offer an objective basis for interpersonal perceptions of welfare (Prendergast, 2005; Robeyns, 2002) thus overcoming limitations of the utilitarian approach, in which this type of comparison is essential for welfare economy, would not be possible.

According to the Capability Approach (Sen, 1999), simply providing a commodity or resource does not directly imply a direct increase in the welfare of a community, due to the multiple manners this resource can be used (capability) and the results obtained by the effective use of this commodity (functioning). Therefore, the assessment of a resource (commodity) and its use depend on a set of cultural, social and knowledge factors, named conversion factors. Thus, from the access conditions to a certain commodity and the referred conversion factors, individuals recognize a set of resources, which will be assessed based on the possibility of access and perception of use. Consequently, reducing this initial set to its capability (Sen, 1999) that is, a smaller set of resources that they will take into consideration to make their choices of use. Based on these capabilities, individuals decide how they will use these resources in order to achieve their functioning, that is, the result of the effective use of these resources, which, in a last analysis, will lead to their utility, for example, exercise of rights, welfare (Reinhard, 2010).

\subsection{ICT Household Survey}

The ICT Household survey, coordinated annually since 2005 by the Regional Center for Studies on the Development of the Information Society (CETIC.br) and Brazilian Internet Steering Committee (CGI.br), aims at mapping the availability of ICT resources by the Brazilian population (i.e. ICT Household Survey 2012) (CGI, 2013).

The survey uses methodological standards developed by the OECD (Organization for Economic Co-operation and Development), Eurostat and by the Observatory for the Information Society in Latin America and the Caribbean (OSILAC), and Economic Commission for Latin America and the Caribbean (ECLAC), thus allowing international comparisons. The sampling plan is based on the national Census and Household Sample Survey. 
The ICT survey collects specific data on citizens' access to and technology usage ability and their preferences regarding access to e-government services, thus allowing the use of the Capability Approach constructs.

Having data on a national scale with statistical significance and a consistent time series provides the robustness of analysis and application of the findings on a national scale.

The abovementioned ICT Household survey data allows the elucidation of the three dimensions used to model the citizens' decision model (Figure 1):

1. Their technical infrastructure resources to access e-government services;

2. Their e-literacy, as a proxy to the ability to make an informed adoption decisions.

3. Their personal preferences in the choice of access to government services.

\section{RESEARCH METHODOLOGY AND REFERENCE MODEL}

The paper's reference model, presented in Figure 1, is based on the Capability Approach (Sen, 1999).

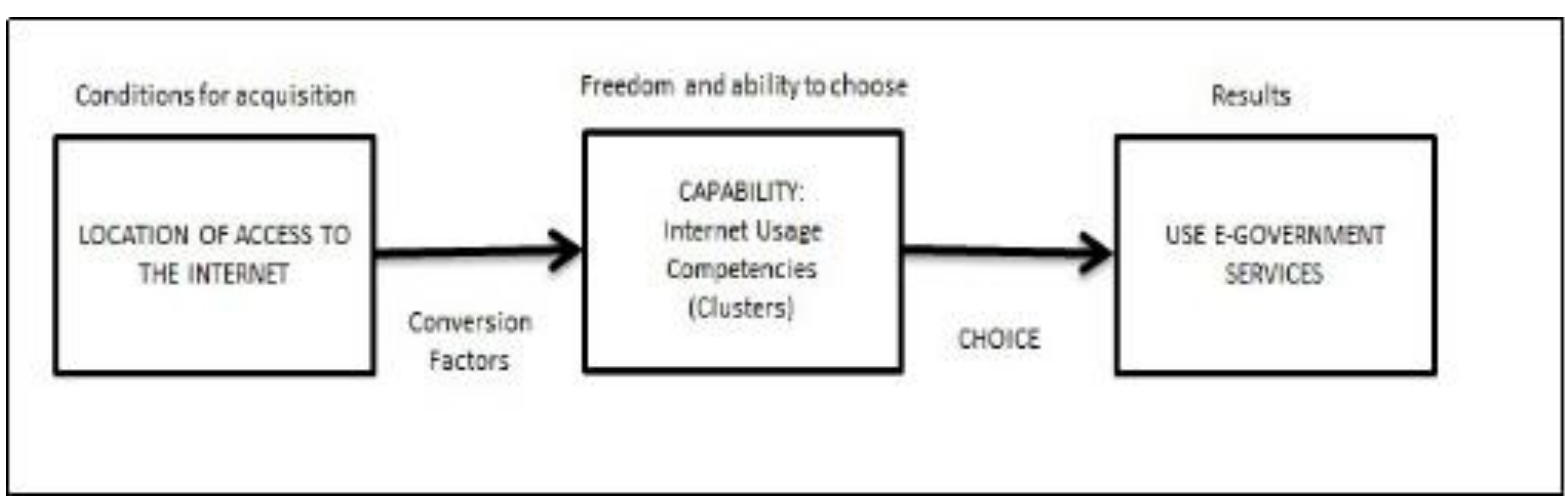

Figure 1 Reference Model: Capability Approach

(Source: adapted from Robeyns (2002))

The objective of this model is to demonstrate the factors influencing individuals' decisions to use electronic government services. The model consists of three constructs: (i) conditions to obtain (or access) the resource; (ii) freedom and ability to choose (capabilities); (iii) results (functioning).

The survey's answer to the question "the most common or favorite access location to theInternet" was used to operationalize the first construct. As a proxy to users' capabilities, the study constructs factors based on the survey's questions regarding the frequent usage of other Internet services: communication, leisure and entertainment activities, information search and online services. This study improves on previous analyses performed by Araujo and Reinhard (2015), where capabilities were represented directly by the usage of e-mail, e-finance, e-commerce services. The last construct 
synthesizes the target phenomenon of this research, that is, the use of e-government services. For that end, this concept was operationalized through a binary variable, indicating whether the Internet users have made use of electronic government services in the last 12 months.

The literature offers a variety of models for the understanding (and prediction) of the individual adoption of innovations, such as TAM (Davis, 1989), UTAUT (Venkatesh, Moris \& Davis, 2003), Rogers (1995). A common thread of these approaches is the focus on the perception of the innovation utility to the potential adopter and the adoption as a learning process.

The study of the adoption of innovations like e-government services on a national scale, factors such as citizens' different access conditions to the technology, their ability to make informed decisions (e-literacy), as well as their values and culture have to be taken into account and will be important to inform public policies.

The Capability Approach (Sen, 1999) recognizes these conditioning factors, as well as the adopters' freedom of choice, such as favoring personal contacts over the use of self-service technology.

This research uses a positivistic approach, a descriptive and exploratory analysis of secondary data (micro-data) from the 2007, 2009 and 2011 editions of the ICT Household Survey, Table 1 presents the survey's variables used in the paper.

Table 1 Variables

\begin{tabular}{|c|c|}
\hline Variables for this study & ICT Survey questions and Categories \\
\hline Social Class & AB (combined), C, and DE (combined); \\
\hline Internet Access Location & $\begin{array}{c}\text { Most common access location (Home, Work, At } \\
\text { someone else's home, Telecenter, Cybercafe, Other } \\
\text { place). }\end{array}$ \\
\hline $\begin{array}{c}\text { Use of Electronic } \\
\text { Government Services }\end{array}$ & Yes/No \\
\hline $\begin{array}{c}\text { Internet Use for } \\
\text { Communication }\end{array}$ & Several \\
\hline $\begin{array}{c}\text { Internet Use for } \\
\text { Information Search and On-line } \\
\text { Services }\end{array}$ & Several \\
\hline $\begin{array}{c}\text { Internet Use for Leisure } \\
\text { and Entertainment }\end{array}$ & Several \\
\hline $\begin{array}{c}\text { Internet Use for Financial } \\
\text { Services }\end{array}$ & Several \\
\hline $\begin{array}{c}\text { Internet Use for Education } \\
\text { and Training }\end{array}$ & Several \\
\hline
\end{tabular}


The first variable presented in Table 1 is a construct derived from respondents' demographic attributes; due to the small sizes of classes $\mathrm{A}$ and $\mathrm{D}$, the data were combined in three groups: Class A-B (upper class); Class C (middle class); Class D-E (lower class).

The variable "Use of Electronic Government Services" is a dichotomous measure that maps the Internet users that have used any of the e-gov services in the last 12 months.

The other (binary) variables represent the different Internet uses, represented by a set of binary metrics that explores several activities connected to communication (e.g. email, instant messages, participation in networking websites), information search and online services (e.g. search for health information), leisure and entertainment (e.g. online games, virtual reality environments), financial services (consultation and transactions via Internet banking), and education and training activities (e.g. school activities, online courses, etc.).

Statistical analysis was performed through multivariate statistical techniques (Binary Factor Analysis, Binary Logistic Regression and Clusters Analysis), using IBM SPSS 19 and Stata package (version 11).

Binary Factor Analysis and the Cluster Analysis were used for the construction of user categories.

Due to the great amount of activities explored in each one of the Internet use patterns, the Binary Factor Analysis technique was applied in order to reduce the problem dimension. Cluster Analysis, using the factorial scores of the latent factors was then applied to identify homogenous Internet user groups regarding the multiple activities performed on the Internet. These clusters were used as proxies for the capabilities of the reference model (Figure 1).

The binary logistic regression technique was used to assess the relationship of the clusters with the users' preferred Internet access locations and also to establish the relationship of the clusters with the use of e-gov services.

Binary logistic regression is a technique that aims at studying the relation between the independent, metric and non-metric variables, and a binary dependent variable (Hair, Black, Babin, Anderson; 2006). In order to perform the logistic regression, a stepwise procedure was used (with $95 \%$ of confidence level). Since the study is not focused on creating predictive models, it was decided to analyze only the odds ratio measure of the statistically significant independent variables.

\section{ANALYSIS AND DISCUSSION OF RESULTS}

In accordance with the objectives of this study, the Internet users were categorized based on their uses of the Internet. The ICT Household Survey lists a number of categories of Internet uses: (i) communication (for example, e-mail, networking websites); (ii) information search and online services; (iii) leisure and entertainment (for example, online games, virtual reality); (iv) financial services (consult and transact via internet banking); (v) education and training activities (for example, online courses). 
Due to the great number of variables in each one of these categories, the Binary Factor Analysis statistical technique (Bartholomew, Steele, Moustaki, \& Galbraith; 2002) was used in order to reduce these variables to a smaller number of latent factors. This analysis was applied to each one of the five abovementioned categories, for each year of the survey (2007, 2009 and 2011); eigenvalues equal to or higher than 1 were used as a criterion for factors retention. Furthermore, where necessary, a Varimax orthogonal rotation was applied, yielding one single significant factor for each category (except for the leisure and entertainment activities category with two factors). The analysis resulted in the following single factors: (a) communication; (b) information search and online services; (c) financial services; and (d) education and training.

For leisure and entertainment activities, the first latent factor gathered all the variables related to the activities with a high degree of interaction and collaboration among Internet users, such as participating in virtual reality environments, online games, etc. The second factor represented the non-interactive activities (for example, listening to online radios, reading news and magazines, etc.). Therefore, the first factor was called "interactive and collaborative activities," and the second one was called "non-interactive activities."

The standardized factor scores derived from the factor analysis were then used as input for the cluster analysis. In order to define the number of clusters, hierarchical clustering was initially applied, defining the "between groups", and the "squared Euclidean distance" as clustering and distance method, respectively. The results suggested the formation of three clusters. Then, the non-hierarchical clustering was applied through k-means algorithm, in order to create the three clusters, whose final positioning is showed in tables 2,3 and 4.

Table 2 Final Cluster Centers (2007)

\begin{tabular}{|l|c|c|c|}
\hline \multirow{2}{*}{} & \multicolumn{3}{|c|}{ Cluster } \\
\cline { 2 - 4 } & 1 & 2 & 3 \\
\hline Communication & 0.10 & -1.08 & 0.48 \\
\hline Information Search and Online Services & -0.28 & -0.98 & 0.68 \\
\hline Interactive and Collaborative Activities (Leisure and Entertainment) & 0.82 & -0.92 & -0.06 \\
\hline Non-interactive Activities (Leisure and Entertainment) & -0.59 & -0.82 & 0.79 \\
\hline Financial Services & -0.07 & -0.65 & 0.37 \\
\hline Training and Education & -0.16 & -0.89 & 0.55 \\
\hline
\end{tabular}

Table 2 shows the differences in profiles of the three user groups: cluster 2 has a negative value for all different Internet use patterns, indicating that this cluster gathers Internet users that make very little use of the analyzed Internet uses. Therefore, these Internet users are characterized as sporadic users. On the other hand, the data on cluster 3 present a positive sign for almost all Internet use activities (except for leisure and entertainment interactive and collaborative activities), indicating that this group has a more Advanced profile when compared to the previous cluster. And, finally, cluster 1 
has an intermediate profile (regarding Internet use patterns) compared to the abovementioned clusters, with a higher leisure and entertainment component.

Table 3 Final Cluster Centers (2009)

\begin{tabular}{|l|c|c|c|}
\hline \multirow{2}{*}{ Communication } & \multicolumn{3}{|c|}{ Cluster } \\
\cline { 2 - 4 } & 1 & 2 & 3 \\
\hline Information Search and Online Services & -0.47 & 0.80 & 0.31 \\
\hline Interactive and Collaborative Activities (Leisure and Entertainment) & 0.09 & 0.55 & -0.44 \\
\hline Non-interactive Activities (Leisure and Entertainment) & -0.69 & 0.96 & 0.56 \\
\hline Financial Services & -0.70 & 0.61 & 0.77 \\
\hline Training and Education & -0.32 & 1.72 & -0.36 \\
\hline
\end{tabular}

The analysis of the 2009 data (Table 3) and 2011 (Table 4) shows a cluster formation similar to 2007 (only with clusters in different order).

Table 4 Final Cluster Centers (2011)

\begin{tabular}{|l|c|c|c|}
\hline \multirow{2}{*}{ Communication } & \multicolumn{3}{|c|}{ Cluster } \\
\cline { 2 - 4 } & 1 & 2 & 3 \\
\hline Information Search and On-line Services & 1.03 & -0.57 & 0.31 \\
\hline Interactive and Collaborative Activities (Leisure and Entertainment) & 1.22 & -0.08 & -0.78 \\
\hline Non-interactive Activities (Leisure and Entertainment) & 0.80 & -0.69 & 0.70 \\
\hline Financial Services & 0.33 & -0.62 & 0.92 \\
\hline Training and Education & 0.14 & -0.44 & 0.70 \\
\hline
\end{tabular}

The Cluster Analysis for each of the three years resulted in a set of three clusters with a similar composition between the years. The observation of the factor loadings led the authors to name them as "Advanced use", "Intermediate use" and "Sporadic use".

Table 5 Electronic government use by Internet user clusters (percentage)

\begin{tabular}{|c|c|c|c|c|c|c|c|c|c|}
\hline & \multicolumn{3}{|c|}{ Advanced Use } & \multicolumn{3}{c|}{ Intermediate Use } & \multicolumn{3}{c|}{ Sporadic Use } \\
\hline & $\mathbf{2 0 0 7}$ & $\mathbf{2 0 0 9}$ & $\mathbf{2 0 1 1}$ & $\mathbf{2 0 0 7}$ & $\mathbf{2 0 0 9}$ & $\mathbf{2 0 1 1}$ & $\mathbf{2 0 0 7}$ & $\mathbf{2 0 0 9}$ & $\mathbf{2 0 1 1}$ \\
\hline Use of e-gov services & 56.4 & 93.7 & 82.7 & 83.7 & 80.3 & 89.4 & 88.8 & 54.3 & 50.7 \\
\hline $\begin{array}{c}\text { Non-use of e-gov } \\
\text { services }\end{array}$ & 43.6 & 6.3 & 17.3 & 16.3 & 19.7 & 10.6 & 11.2 & 45.7 & 49.3 \\
\hline
\end{tabular}


Table 5 shows the percentage distribution of e-gov services users in each one of the proposed Internet user clusters. The analysis of table 5 data shows that e-gov services are widely used by the Internet users with the advanced and intermediate use profile. On the other hand, in the Internet user group of sporadic use, the use of e-gov services has decreased. Therefore, Table 5 data shows that the proportion of Internet use of e-gov services is much higher among those with higher proficiency in the Internet use (advanced and intermediate users groups).

Table 6 Internet Access Location by Internet user clusters (percentage)

\begin{tabular}{|c|c|c|c|c|c|c|c|c|c|}
\hline & \multicolumn{3}{|c|}{ Advanced use } & \multicolumn{3}{c|}{ Intermediate use } & \multicolumn{3}{c|}{ Sporadic use } \\
\hline & $\mathbf{2 0 0 7}$ & $\mathbf{2 0 0 9}$ & $\mathbf{2 0 1 1}$ & $\mathbf{2 0 0 7}$ & $\mathbf{2 0 0 9}$ & $\mathbf{2 0 1 1}$ & $\mathbf{2 0 0 7}$ & $\mathbf{2 0 0 9}$ & $\mathbf{2 0 1 1}$ \\
\hline Home & 25.5 & 56.3 & 75.6 & 39.0 & 52.4 & 67.8 & 43.8 & 35.9 & 54.9 \\
\hline Work & 13.6 & 28.6 & 10.6 & 25.1 & 18.7 & 22.8 & 25.8 & 12.3 & 13.3 \\
\hline School & 4.0 & 0.6 & 1.0 & 3.3 & 3.1 & 0.9 & 2.7 & 2.7 & 1.3 \\
\hline Someone else's home & 12.7 & 5.4 & 3.6 & 7.8 & 6.7 & 2.2 & 6.2 & 12.5 & 9.3 \\
\hline Telecenter & 1.6 & 0.0 & 0.4 & 1.2 & 0.7 & 0.1 & 1.1 & 1.3 & 0.5 \\
\hline Cybercafé & 40.9 & 8.8 & 7.2 & 22.9 & 18.1 & 4.9 & 20.2 & 34.5 & 18.5 \\
\hline Other Locations & 1.7 & 0.2 & 1.5 & 0.7 & 0.4 & 1.2 & 0.2 & 0.8 & 2.2 \\
\hline
\end{tabular}

Table 6 data shows the Internet access location distribution for each group. The data clearly show an increase of Internet use preferably at home in all groups. However, Internet use at home is much higher for the advanced use group (75.6\% in 2011) and intermediate group (67.8\% in 2011) than the sporadic use group (54.9\% in 2011). Table 6 also shows that Cybercafés are, in percentage terms, the second most important access location for this (underprivileged) last group.

Table 7 Internet Access Location by Internet user clusters (percentage)

\begin{tabular}{|l|r|r|r|r|r|r|r|r|r|}
\hline & \multicolumn{3}{|c|}{ Advanced use } & \multicolumn{3}{|c|}{ Intermediate use } & \multicolumn{3}{c|}{ Sporadic use } \\
\hline & 2007 & 2009 & 2011 & 2007 & 2009 & 2011 & 2007 & 2009 & 2011 \\
\hline Class A-B & 29.5 & 64.0 & 52.5 & 45.6 & 45.7 & 64.3 & 53.0 & 32.0 & 36.4 \\
\hline Class C & 54.8 & 33.5 & 44.0 & 47.4 & 47.7 & 33.5 & 38.0 & 56.1 & 54.2 \\
\hline Class D-E & 15.8 & 2.5 & 3.5 & 7.0 & 6.5 & 2.2 & 9.0 & 11.8 & 9.4 \\
\hline
\end{tabular}

Table 7 presents Internet user groups in relation to the socioeconomic status of their members, showing that the three groups are composed mainly of class A-B members (upper class) and class $C$ (middle class). The proportion of Internet users in class D-E (lower class), though small in all clusters, is greater in the Internet user group of sporadic use.

\subsection{Use of Electronic Government Services}


The paper's objective was to assess the survey's respondents' decision to use egovernment services, based on their preferred Internet access location, mediated by their patterns of Internet usage patterns (use groups).

For this purpose, binary logistic regression was used, yielding odds ratios, to measure how much, maintaining the other conditions constant, each one of the explanatory variables increases the chance of occurrence (or probability) of the studied phenomenon (e-government usage). Tables 8, 9 and 10 show the odds ratio values (of statistically significant attributes at $95 \%$ of reliability) of different Internet access locations according to the probability of the individual belonging to each one of the analyzed Internet groups.

Table 8 Contribution of the Internet access location to the Advanced Internet user group (odds ratio)

\begin{tabular}{|l|c|c|c|c|c|c|}
\hline & \multicolumn{3}{|c|}{ C } & \multicolumn{3}{c|}{ DE } \\
\hline & $\mathbf{2 0 0 7}$ & $\mathbf{2 0 0 9}$ & $\mathbf{2 0 1 1}$ & $\mathbf{2 0 0 7}$ & $\mathbf{2 0 0 9}$ & $\mathbf{2 0 1 1}$ \\
\hline At Home and Work & 0.43 & 3.34 & 2.24 & 0.28 & & \\
\hline At someone else's home & & & & & & \\
\hline Cybercafé & & & & & & \\
\hline Telecenter & & & & & & \\
\hline
\end{tabular}

Table 9 Contribution of the Internet access location to the Intermediate Internet user group (odds ratio)

\begin{tabular}{|l|c|c|c|c|c|c|}
\hline & \multicolumn{3}{|c|}{ C } & \multicolumn{3}{c|}{ DE } \\
\hline & $\mathbf{2 0 0 7}$ & $\mathbf{2 0 0 9}$ & $\mathbf{2 0 1 1}$ & $\mathbf{2 0 0 7}$ & $\mathbf{2 0 0 9}$ & $\mathbf{2 0 1 1}$ \\
\hline At Home and Work & 1.55 & & 2.25 & & & 5.50 \\
\hline At someone else's home & & 0.51 & & & & \\
\hline Cybercafé & & 0.48 & & & & \\
\hline Telecenter & & 0.24 & & & & \\
\hline
\end{tabular}


Table 10 Contribution of the Internet access location to the sporadic Internet user group (odds ratio)

\begin{tabular}{|l|c|c|c|c|c|c|}
\hline & \multicolumn{3}{|c|}{ C } & \multicolumn{3}{c|}{ DE } \\
\hline & $\mathbf{2 0 0 7}$ & $\mathbf{2 0 0 9}$ & $\mathbf{2 0 1 1}$ & $\mathbf{2 0 0 7}$ & $\mathbf{2 0 0 9}$ & $\mathbf{2 0 1 1}$ \\
\hline At Home and Work & 2.11 & 0.33 & 0.36 & 2.70 & 0.43 & 0.35 \\
\hline At someone else's home & & & & & & \\
\hline Cybercafé & & & & & & \\
\hline Telecenter & & & 4.71 & & & \\
\hline
\end{tabular}

The data in Tables 8, 9 and 10 shows that the preferred Internet use at home or at work (individual access) has a positive impact on the chance of belonging to the Internet user group of advanced and intermediate use. On the other hand, Table 10 showed that Internet use at home or at work implies the reduction in the probability of belonging to the Internet sporadic use group. Therefore, based on Sen's Capability approach, these findings demonstrate that the individual access to the internet (preferably at home or work) encourages the development of capabilities.

Table 11 Contribution of different Internet user groups to the decision of using egov services (odds ratio)

\begin{tabular}{|c|c|c|c|c|c|c|}
\hline & \multicolumn{3}{|c|}{ C } & \multicolumn{3}{c|}{ DE } \\
\hline Groups (Clusters) & $\mathbf{2 0 0 7}$ & $\mathbf{2 0 0 9}$ & $\mathbf{2 0 1 1}$ & $\mathbf{2 0 0 7}$ & $\mathbf{2 0 0 9}$ & $\mathbf{2 0 1 1}$ \\
\hline Advanced Use & 0.17 & 6.80 & 2.93 & 0.31 & 7.15 & 4.23 \\
\hline Intermediate Use & 3.71 & 2.50 & 4.60 & 3.20 & 3.37 & 10.93 \\
\hline Sporadic Use & 4 & 0.24 & 0.19 & & 0.23 & 0.12 \\
\hline
\end{tabular}

The data in Table 11 shows that belonging to the proposed Internet user groups (capability measure) positively impacts the use of electronic government services. Odds ratio values were much higher among the members of the intermediate and advanced use groups, respectively. The probability of using e-gov services was shown to be greater among the users of the intermediate use group, compared to the advanced Internet users. An analysis of the data in Tables 3 and 4 emphasizes that the main difference between these two groups is the intensity use of interactive and collaborative activities of leisure and entertainment (for example, online games, virtual environment). Therefore, such competence could benefit the use of e-gov services in the intermediate Internet user group. On the other hand, the data showed odds ratio lower than 1 for Internet users of sporadic use, indicating that belonging to this group implies a reduction in the potential use of e-gov services. In other words, the data emphasizes that lower competence Internet users tend not to use e-gov services.

The findings of this research demonstrate the adequacy of Sen's Capability Approach as the theoretical framework to analyze the adoption of e-gov services in Brazil. Based on the mediating chain (Figure 1) the results show that the individual 
access to the Internet (Internet access most frequently at home or in the workplace) allows the development of capabilities. In other words, increasing the likelihood of the Internet user to be a part of the sophisticated or intermediate internet users group. Consequently, these capabilities favor the decision to use e-gov services, achieving the functioning in the abovementioned mediated chain.

\section{CONCLUSIONS}

The objective of this research was to categorize Brazilian Internet users according to the diversity of their online activities and to assess the propensity of these Internet users' groups to use e-gov services. The results of this research showed the formation of three different groups of Internet users, called (i) Advanced use, (ii) Intermediate use, and (iii) Sporadic use. The first group gathers Internet users with most competence in Internet use, that is, those who make use of all or almost all analyzed Internet use patterns. The second group consists of Internet users that perform a lower number of activities on the Internet, but that are characterized by the most extensive use of interactive and collaborative activities of leisure and entertainment, such as participating in virtual reality environments and online games. Finally, the last group comprises the Internet users with a more mundane (sporadic) use of the Internet, limiting themselves to the performance of few activities on the Internet (when compared with the previous groups). Regarding the propensity to use e-gov services, the results showed that the Internet users belonging to the advanced and intermediate use groups were more likely to use the e-gov services. On the other hand, the Internet users of the sporadic use group were less likely to use e-gov services. These results strengthen the notion that the development of Internet use competence has a positive impact on the propensity to use e-gov services. The results also demonstrated that the Internet user group of intermediate use presented a higher tendency to use e-gov services than the Internet user group of advanced use. Such tendency is possibly related to the extensive use of interactive and collaborative activities of leisure and entertainment performed by these users.

In summary, the paper showed the users' preferences for Internet access location and the capabilities that favor their use of e-government services.

These findings indicate the appropriateness of enacted public policies that have addressed Internet access problems through varied initiatives: at the regulatory and fiscal levels, connectivity rates, especially mobile, which have dropped significantly due to increased competition among service providers (the creation of a state-owned nationwide broadband network, mandatory users' free mobility between providers), reduction of taxes on entry-level computers, tablets and communication services. There are large direct public investments in connectivity for schools, free wi-fi access in public place, with satellite connection being provided to remote rural areas (e.g. Brazilian Amazon Region). Schools with increased connectivity are then able to promote computer literacy. More affordable access to devices and Internet connection contributed to the widespread use of communication services, especially social network services, on mobiles (mostly smartphones but also tablets). As a response, e-gov services are increasingly being offered to social class $\mathrm{D}$ and $\mathrm{E}$ citizens for mobile devices. 
The results also demonstrate the importance of considering the specific dimensions of the Capability Approach for the understanding of the adoption of egovernment services:

1. The condition of access to the services (Internet access from home or work)

2. The ability to make informed decisions (patterns of Internet services usage - e-literacy)

\section{Personal preferences}

These findings represent a contribution to the modeling of citizens' innovation adoption decisions, through the inclusion of new factors. These factors represent both possibilities for intervention (infrastructure provision) and limitations (individual capabilities and preferences) for intervention of public policy makers, who have to be considered in the analysis of e-government services provision.

\section{REFERENCES}

Araujo, M. H., \& Reinhard, N. (2013). Factors Influencing the Use of Electronic Government Services in Brazil. REGE Revista de Gestão, 22(4), pp. 585-596, 2015

Avgerou, C., Ganzaroli, A., Poulymenakou, A., \& Reinhard, N. (2009). Interpreting the trustworthiness of government mediated by Information and Communication Technology: Lessons from electronic voting in Brazil, Information Technology for Development, 15, 133-148

Barbosa, A. F., Pozzebon, M., Diniz, E. H. (2013). Rethinking e-government performance assessment from a citizen perspective. Public Administration, 91(3), 744762.

Bartholomew, D., Steele, F., Moustaki, I., \& Galbraith, J. (2002). The Analysis and Interpretation of Multivariate Data for Social Scientists. London: Chapman and Hall/CRC Press, London.

CGI. (2013). Survey on the use of Information and Communication Technologies in Brazil: ICT Households and Enterprises 2012. Sao Paulo: Brazilian Internet Steering Committee.

Cunha, M. A. V. C., Miranda, P. R. M. (2013). Uso de TIC pelos governos: uma proposta de agenda de pesquisa a partir da produção acadêmica nacional. Organizações \& Sociedade, 20(66), 543-566

Davis, F. D. (1989). Perceived usefulness, perceived ease of use, and user acceptance of Information Technology. MIS Quartely, 13(3), 319-340

Hair, J. F., Black, W. C., Babin, J. B., Anderson, R. E., \& Tatham, R. L. (2006). Multivariate Data Analysis. New Jersey: Pearson Prentice Hall.

Lemos, R., \& Martini, P. (2010). LAN Houses: A new wave of Digital Inclusion in Brazil. Information Technologies \& International Development, 6, 31-35 
Madon, S., Reinhard, N., Roode, D., \& Walsham, G. (2009). Digital inclusion projects in developing countries: Processes of institutionalization. Information Technology for Development, 15, 319-340

Mori, C. K., \& Assumpção, R.O. (2007). Brazilian Digital Inclusion Public Policy : achievements and challenges. The Journal of Community Informatics, 3(3), 1-6

Prendergast, R. (2005). The concept of freedom and its relation to economic development - a critical appreciation of the work of Amartya Sen. Cambridge Journal of Economics. 29(6),1145-1170

Reinhard, N., \& Moya, R. W. (2002). The Adoption of Electronic Filing For Individual Income Tax Returns In Brazilian. In: International Conference on E-Business (ICEB), pp.1-7. Proceedings of ICEB 2012, Beijing

Reinhard, N. (2010). The Challenges of Universal Access: Models and Management an invitation research. In: CGI. Survey the Use of Information and Communication Technologies in Brazil 2005-2009, São Paulo: CGI, 189-198

Robeyns, I. (2002). The Capability Approach: a theoretical survey. Journal of Human Development, 6(1), 93-117

Rogers, E. M. (1995). Diffusion of Innovations $\left(4^{\text {th }}\right.$ ed). New York: Free Press, 1995

Sen, A. K. (1999). Development as freedom. Oxford : Oxford University Press.

Venkatesh, V., Morris, M., Davis, G. B., \& Davis, F. (2003). User acceptance of information technology: toward a unified view. MIS Quartely, 27(3), 425-478 